\title{
A review of spatial technologies with applications for malaria transmis- sion modelling and control in Africa
}

\author{
Michael T. Gebreslasie \\ School of Agricultural, Earth and Environmental Sciences, University of KwaZulu-Natal, Durban, South \\ Africa
}

\begin{abstract}
Spatial technologies, i.e. geographic information systems, remote sensing, and global positioning systems, offer an opportunity for rapid assessment of malaria endemic areas. These technologies coupled with prevalence/incidence data can provide reliable estimates of population at risk, predict disease distributions in areas that lack baseline data and provide guidance for intervention strategies, so that scarce resources can be allocated in a cost-effective manner. This review focuses on the spatial technology applications that have been used in epidemiology and control of malaria in Africa. Peer-reviewed papers identified through a PubMed search using the following keywords: geospatial technology OR Geographic Information Systems OR Remote Sensing OR Earth Observation OR Global Positioning Systems OR geospatial modelling $\mathrm{OR}$ malaria incidence $\mathrm{OR}$ malaria prevalence $\mathrm{OR}$ malaria risk prediction OR malaria mapping AND malaria AND Africa were used. These included mapping malaria incidence and prevalence,
\end{abstract}

Correspondence: Michael T. Gebreslasie, School of Agricultural, Earth and Environmental Sciences, University of KwaZulu-Natal, Westville Campus, P. B. X54001, Durban, 4000, South Africa.

Tel: +27.31 .2608276 .

E-mail: gebreslasie@ukzn.ac.za

Key words: Malaria; Geographic information systems; Remote sensing; Mapping and prediction; Africa.

Acknowledgements: this study was partially funded by the European Commission, under the Seventh Framework Programme (FP 7). The author is grateful to the MALAREO consortium.

Note: the present paper includes results from MALAREO (2011-2013; http://cordis.europa.eu/project/rcn/97892_en.html), a project in the Seventh Framework Programme of the EU, aiming to stimulate and facilitate the use of earth observation in malaria control and management in South-Africa, Swaziland and Mozambique.

Received for publication: 4 February 2015.

Revision received: 14 August 2015.

Accepted for publication: 29 August 2015.

(C) Copyright M.T. Gebreslasie, 2015

Licensee PAGEPress, Italy

Geospatial Health 2015; 10:328

doi:10.4081/gh.2015.328

This article is distributed under the terms of the Creative Commons Attribution Noncommercial License (by-nc 3.0) which permits any noncommercial use, distribution, and reproduction in any medium, provided the original author(s) and source are credited. assessing the relationship between malaria and environmental variables as well as applications for malaria early warning systems. The potential of new spatial technology applications utilising emerging satellite information, as they hold promise to further enhance infectious risk mapping and disease prediction, are outlined. We stress current research needs to overcome some of the remaining challenges of spatial technology applications for malaria so that further and sustainable progress can be made to control and eliminate this disease.

\section{Introduction}

Malaria poses serious economic, social and health burdens in tropical and subtropical countries where it is predominantly found (Gallup and Sachs, 2001). Recognising the impact of malaria on public health and economy, most African countries, with the help of interested international groups, have initiated numerous action plans as a malaria control and elimination strategy (Mendis et al., 2009). The World Health Organization (WHO) world malaria report of 2012 shows that malaria is presently endemic in 104 countries worldwide, while it is transmitted in 99 of them. According to this report, the majority of countries listed are classified as being in the malaria control phase, ten countries in the malaria pre-elimination phase and another ten countries in the malaria elimination phase. Five countries do not have ongoing transmission and are classified as being in the prevention of re-introduction phase (WHO, 2012). Although efforts of combating malaria have yielded dramatic decreases in the number of cases and deaths in most endemic regions, devastating statistics reported in the WHO (2012) report that 655,000 died from this disease, with $86 \%$ of the victims being children under 5 years of age. Furthermore, $80 \%$ of the cases reported and $91 \%$ of the total deaths of the 216 million cases worldwide occurred in Africa.

It is widely acknowledged that the malaria transmission dynamics are closely related to socioeconomic, climatic and environmental factors; the latter including altitude, precipitation, temperature and land use and land cover (Craig et al., 2004; Mboera et al., 2010). Malaria has, therefore, been defined as an environmental disease (Hay et al., 2000; Craig et al., 2004; Moshe and Andrew, 2004; Raso et al., 2012). About $70-90 \%$ of the risk of malaria is considered due to environmental factors which in turn influence the abundance and survival of the vectors (Smith et al., 2004; Ye et al., 2007). Hence, a deeper knowledge of environmental variables, conducive to mosquito vector life cycle, is important to target control interventions. Modelling environmental variables are very valuable in defining foci of malaria transmission. The development of spatial analytical techniques has created an avenue to evaluate environmental variables that are generated by remote sensing satellite sensors and captured by Geographic Information Systems (GIS) for spatial and temporal environmental analysis (Tanser and le Sueur, 2002; Thomas et al., 2002). These tech- 
nologies provide tools for the identification and quantification of the population at risk of parasite infections in endemic communities (Tanser and le Sueur, 2002; Riedel et al., 2010). In the case of malaria in Africa, these tools have been used to model and develop malaria risk maps at different spatial scales. These include continental level (MARAARMA, 2008) and national spatial model (Gosoniu et al., 2010; Riedel et al., 2010; Stensgaard et al., 2011) which were used to construct malaria risk maps using data from a sample of a population with interpolation to areas where malaria case and prevalence data were captured. This facilitated detection of malaria risk areas and prediction of malaria transmissions both spatially and temporally, which in turn, provided guidance to malaria control managers in decision-making and policy planning for cost-effective resources allocation (Mills et al., 2008). In many studies in Africa, particular emphases have been given in mapping incidence and/or prevalence (Craig et al., 1999; Yeshiwondim et al., 2009), identification of mosquito habitats (Hayes et al., 1985; Hay et al., 2000), and spatio-temporal prediction/forecasting transmission risk in relation to environment (Mboera et al., 2010; Riedel et al., 2010; Stensgaard et al., 2011). The advent of new spatial data sources with spatial statistics and geo-statistics offered great potential to increase our understanding of the link between malaria disease and environmental variables. To benefit from these technologies, it is essential to evaluate and assess the impact of these spatial technologies precisely. Thus, the purpose of this article is to appraise the various spatial technology applications, and hence discuss their contributions in improving the current level of understanding of epidemiology and malaria control in Africa.

This review is organised in the following main sections. In the first section, the paper summarises applications of spatial technology for recording spatial locations and mapping malaria incidence and/or prevalence in Africa. The next section reviews applications of spatial technology for assessing the relationships between malaria incidence and/or prevalence and environmental variables in Africa. The third section reviews applications of spatial technology for spatio-temporal malaria risk modelling in Africa. Finally, current research needs to overcome some of the challenges in malaria control and elimination encountered in the continent are discussed.

\section{Selection criteria for the literature search undertaken}

This review is based on a systematic search for relevant literature in the PubMed electronic search engine (http://www.ncbi.nlm.nih.gov /pubmed). This search considered the studies conducted for the period 2005 to 2014 using geospatial technologies with applications for malaria transmission modelling and control in Africa based on the following combination of terms and Boolean operations: geospatial technology OR Geographic Information Systems OR Remote Sensing OR Earth Observation 0R Global Positioning Systems OR geospatial modelling OR malaria incidence $\mathrm{OR}$ malaria prevalence $\mathrm{OR}$ malaria risk prediction OR malaria mapping AND malaria AND Africa. Any piece of literature that did not satisfy these criteria was not selected. Literature on malaria without the element of geo-spatial analysis such as WHO world malaria report, Roll Back Malaria and Malaria Atlas project were used to strengthen the discussion and understanding why geo-spatial technology has been and/or can be used to understand the malaria transmission risk modelling. The relevant literature was used to determine the levels of application and use of geospatial technology in malaria transmission modelling and mapping.

\section{Search results}

The search for literature conducted for the period 2005-2014 revealed 458 hits of which 46 were considered relevant. The relevant publications (46) were further categorised into the three area of application, i.e. for mapping malaria incidence and prevalence, for assessing the relationship between malaria and environmental variables, and for malaria early warning systems. The subsequent sections gives a detailed discussion based on the selected publications and their applications on the study of malaria in Africa continent.

\section{Spatial technologies for mapping malaria incidence and prevalence}

The purpose of using GIS in malaria epidemiological studies is that maps provide an added spatial context to data analysis, which helps to visualise the complex disease patterns. Snow et al. (1996) recognised that accurate mapping of malaria cases is an important tool to improve malaria vector control interventions. Mapping the incidence and/or prevalence rate of malaria is the most basic application that focuses in examining past trend as well as enlightening the present situation. This basic approach does not include any geo-statistical analysis, except correlating incidence and/or prevalence with population to calculate population at risk (Craig et al., 1999). A summary of various studies that applied spatial technologies for malaria incidence and/or prevalence mapping are summarised in Table 1. For each study, the objective, country, method and scale of application/data sources are given.

The most extensive work on spatial variation for malaria risk assessment in Africa has been made at continental level. Malaria risk maps were produced at coarse spatial resolution and thus have limited operational use to support malaria control programme activities at lower administrative levels. Attempts to produce maps at local levels were reported by various authors, some are based on specific geo-referenced point prevalence data (Kazembe et al., 2006; Craig et al., 2007; Noor et al., 2008; Yeshiwondim et al., 2009), while others are based on monthly clinical malaria cases reported from health facilities (Oesterholt et al., 2006; Thomson et al., 2006). For instance, Craig et al. (2007) used GIS for mapping historic malaria cases in Botswana using malaria cases reported at local health facilities. Similarly, Noor et al. (2008) produced a continuous map of malaria prevalence across Somalia based on a dataset obtained from a national malaria cluster sample survey in 2005 and routine cluster survey in 2007. The map revealed that malaria transmission in Somalia varied from hypo- to meso-endemic. The map explicitly illustrated that malaria prevalence in Somalia was primarily located near Juba and Shabella rivers. Yeshiwondim et al. (2009) mapped malaria incidence at village level in an area with unstable malaria transmission in central part of Ethiopia. These authors developed a structured village global positioning system (GPS) survey questionnaire that was used to record the location information and other relevant demographic data. After calculating a malaria incidence density of 1000 people per year for each geo-referenced village, a spatial clustering method was used to map malaria incidence. Mapping malaria incidence and/or prevalence have led to growing interest in modelling the association between malaria incidence and/or prevalence and other potential related variables.

Mapping malaria incidence/prevalence is an integral part of spatial decision support system (SDSS). Kelly et al. (2012) reviewed existing SDSS for the support of malaria elimination, and stated its effectiveness for improved planning, implementation, monitoring and evaluation of interventions. However, further study is required in order to 
operationally use the full potential of SDSS as an applied health system. Trial SDSS applications have been implemented in some malaria control programmes in Southern Africa (Booman et al., 2003). A GPSbased tracking of malaria cases and the collection of location-based entomological data allows a more precise and thus reliable assessment of the relationship between malaria and its environmental drivers.

\section{Spatial technologies for the assessment of the rela- tionship between malaria and environmental variables}

The transmission dynamic of malaria endemic is closely linked with the distribution and abundance of mosquito, which in turn is linked to the existence of suitable habitats and appropriate environmental characteristics. Several studies have found an association between mosquito distribution and/or abundance and climatic factors. Mosquitoes need water for reproduction, whereas turbulent water can wash away larvae population. Optimal temperature range for the development of Anopheles mosquito and the parasite is approximately between 20 and $30^{\circ} \mathrm{C}$, with thermal death occurring at temperatures either below 16 or above $40^{\circ} \mathrm{C}$ (Blanford et al., 2013). Evaluating climatic factors that affect parasite transmission, a number of studies have developed country-level risk maps about malaria transmission (Craig et al., 1999; Guerra et al., 2006). A summary of the studies are provided in Table 2 with an emphasis on the assessment of the association of malaria incidence and/or prevalence with climatic and environmental characteristics through appropriate combinations of spatial technologies. Many of the studies reviewed focused either on country or regional level approaches in Africa. The principal objectives of these studies were to assess the statistical relationships between malaria incidence and/or prevalence and other variables including temperature, rainfall, land use/land cover, potential breeding sites (water bodies), altitude, demographics, climate change, malaria control interventions, and remote sensing.

Noboru et al. (2005) were the first authors that used high spatial resolution satellite remote sensing imagery to map the distribution of anopheline larva habitats in the Western part of Kenyan highlands. IKONOS (http://global.digitalglobe.com/sites/default/files/DG_ IKONOS_DS.pdf) imagery was used to develop different land use and land cover classes such as farmlands, forests, pastures, roads, and natural swamps. The GIS point pattern analysis was executed to determine whether the distribution pattern of anopheline larva, which was collected from field, was clustered in any of the land use/ land cover classes. Similarly a study by Bøgh et al. (2007) employed satellite remote sens- ing imagery in conjunction with GIS, and applied a proximity analysis to develop a high spatial resolution map of malaria transmission risk areas in the highlands of Gambia. Maximum likelihood supervised classification was carried out on Landsat Thematic Mapper (TM) satellite (https://ta.cr.usgs.gov/TM) imagery to map mosquito breeding habitats for Anopheles gambiae s.l., the major malaria vector in the area. Moreover Oesterholt et al. (2006) developed a model to describe the spatial and temporal variation of malaria transmission in two villages in Northern Tanzania. The demographics, entomological, and parasitological data of these villages were collected over the course of a year. Houses where mosquito traps were installed, reported malaria cases, and rivers within these villages were registered using GPS. GIS was used to develop a map and calculate the distance of individual households to the river and subsequently categorised as close $(<1200$ $\mathrm{m})$, intermediate $(1200-1600 \mathrm{~m})$ and far (>1600 m). Finally, logistic regression models were used to determine the association between malaria incidence and housing conditions, age, and distance to the river. Their results showed that malaria cases were negatively associated to the distance to the river throughout the year in the villages.

In Mali, Sogoba et al. (2007) conducted a study to identify environmental determinants for the spatial and temporal relative frequency of A. gambiae s.s. and A. arabiensis mosquitoes with the principal objective to produce spatio-temporal distribution maps. The relative frequency of these mosquito species were computed from the collated larvae in the study area. Ecological variables such as temperature, rainfall, and soil water index at $5 \times 5 \mathrm{~km}$ spatial resolution, land use and land cover at 1 $\mathrm{x} 1 \mathrm{~km}$ spatial resolution, and the normalised difference vegetation index (NDVI) at $8 \times 8 \mathrm{~km}$ spatial resolution were extracted for the study area from existing continental datasets. Logistic regression was applied to identify the environmental variable which determines the relative frequency of $A$. gambiae s.s. and $A$. arabiensis mosquitoes. Soil water index, and minimum and maxima temperatures were significantly associated with the relative frequency of $A$. gambiae and $A$. arabiensis. Finally, a Bayesian geo-statistical model was used to produce maps of the spatial distribution of these species. In the same study area, Sogoba et al. (2008) assessed the relationship between relative frequencies of the different chromosomal forms of A. gambiae including Mopti, Bamako, Savanna, and their hybrids with the same climate and environmental dataset as described in their previous work. These authors applied a bivariate multinomial regression model to assess any relationship between the parameters, and the result revealed that each chromosomal form favours a particular defined eco-climatic zone.

Kazembe (2007) analysed the relationship between malaria risk and

Table 1. Geographic information system-based studies for mapping malaria incidence/prevalence.

\begin{tabular}{|c|c|c|c|c|}
\hline Type of data and source & Objective & Study area & Method & Reference \\
\hline Point-referenced prevalence data & Mapping of malaria risk & Malawi & Interpolation methods & Kazembe et al. (2006) \\
\hline $\begin{array}{l}\text { Demographic data; } \\
\text { clinical cases; vector light traps; } \\
\text { distance to breeding sites }\end{array}$ & Mapping of malaria cases & Tanzania & Crude mapping malaria risk & Oesterholt et al. (2006) \\
\hline $\begin{array}{l}\text { Malaria prevalence } \\
\text { (extracted from MARA/ARMA) }\end{array}$ & Mapping of historical malaria prevalence & Botswana & Univariate logistic regression & Craig et al. (2007) \\
\hline $\begin{array}{l}\text { Number of monthly clinical } \\
\text { malaria cases }\end{array}$ & $\begin{array}{l}\text { Stratification of epidemic } \\
\text { areas based on cases }\end{array}$ & Eritrea & Cluster analysis and mapping & Thomson et al. (2006) \\
\hline $\begin{array}{l}\text { Outcome of rapid diagnostic tests } \\
\text { for } \text { P. falciparum parasites } \\
\text { (malaria survey data) }\end{array}$ & $\begin{array}{l}\text { Mapping of the malaria distribution } \\
\text { Mapping of the malaria distribution } \\
\text { in low transmission areas }\end{array}$ & Somalia & $\begin{array}{l}\text { Routine spatial clustering } \\
\text { of malaria prevalence }\end{array}$ & Noor et al. (2008) \\
\hline Geo-referenced prevalence data & $\begin{array}{l}\text { Mapping of the local pattern } \\
\text { of malaria distribution }\end{array}$ & Ethiopia & $\begin{array}{c}\text { Spatial cluster analysis of the } \\
\text { malaria incidence }\end{array}$ & Yeshiwondim et al. (2009) \\
\hline
\end{tabular}

MARAARMA, Mapping Malaria Risk in Africa/Atlas du Risque de la Malaria en Afrique. 
aggregated environmental variables, such as altitude, precipitation and soil water capacity using spatial regression models, in northern Malawi at the sub-district level. These explanatory variables were interpolated with gridded surfaces generated from long-term monthly means of historical weather stations. Finally, a profile of spatial variation of malaria risk was developed using ecological spatial regression model. The results showed that malaria risk increased with altitude, precipitation, and soil water capacity. On the other hand, Craig et al. (2007) argued about the shortfall of variable selection due to over-fitting, confounding and co-linearity in the data for the purpose of malaria prevalence map- ping. These authors used univariate logistic regression and step-wise selection on bootstrap in order to find the most plausible and reliable predictors of malaria prevalence, resulting in a final model of three predictor variables having different spatial resolutions namely summer rainfall, mean annual temperature and altitude. Finally, a Bayesian model was applied to the selected variables to map historical malaria risks. Similarly, Silue et al. (2008) used Bayesian model to produce spatially explicit risk maps of malaria transmission in a rural part of Western Côte d'Ivoire. Initially, these authors examined the association of malaria prevalence data with numerous malaria transmission risk

Table 2. Relationship between malaria and environmental variables.

\begin{tabular}{|c|c|c|c|c|}
\hline Type of data and source & Objective & Study area & Method & Reference \\
\hline $\begin{array}{l}\text { Land cover (farmlands, forests, pastures, } \\
\text { roads and natural swamps) }\end{array}$ & $\begin{array}{l}\text { Mapping of the distribution } \\
\text { of the habitats of anopheline larva }\end{array}$ & Kenya & $\begin{array}{l}\text { Remote sensing and } \\
\text { point pattern spatial analysis }\end{array}$ & Noboru et al. (2005) \\
\hline $\begin{array}{l}\text { Malaria cases; vector light traps; } \\
\text { meteorological data; demographic data }\end{array}$ & $\begin{array}{l}\text { Mapping of the spatial and temporal } \\
\text { variation of malaria transmission }\end{array}$ & Tanzania & $\begin{array}{l}\text { Gauging malaria cases by residence, } \\
\text { season and distance to breeding site }\end{array}$ & Oesterholt et al. (2006) \\
\hline $\begin{array}{l}\text { Vector breeding habitats } \\
\text { and human settlements }\end{array}$ & Mapping the malaria transmission risk & Gambia & $\begin{array}{l}\text { Mapping of malaria transmission } \\
\text { risk by questionnaires }\end{array}$ & Bøgh et al. (2007) \\
\hline
\end{tabular}

Summer rainfall;

altitude; mean annual temperature;

Mapping of historical malaria prevalence Botswana Univariate logistic regression

Bayesian geo-statistical model

Craig et al. (2007)

malaria prevalence

(extracted MARA/ARMA)

Malaria incidence; altitude;

precipitation; soil water capacity

Vector abundance and frequency;

rainfall; temperature; water body;

agro-ecological zone;

NDVI; soil water index

Incidence of clinical malaria;

temperature; rainfall

$$
\begin{aligned}
& \text { Profiling spatial variation } \\
& \text { of the malaria risk }
\end{aligned}
$$

$\begin{array}{ccc}\begin{array}{c}\text { Assessing the spatial distribution } \\ \text { of An. gambiae s.s. and An. Arabiensis }\end{array} & \text { Mali } & \begin{array}{c}\text { Bayesian geo-statistical } \\ \text { logistic regression modelling }\end{array}\end{array}$

\begin{tabular}{lcccc}
$\begin{array}{l}\text { Adult mosquito survey } \\
\text { (indoor pyrethrum spray } \\
\text { collection method) } \\
\text { and aquatic habitats }\end{array}$ & $\begin{array}{c}\text { Mapping the spatial distribution } \\
\text { and abundance of mosquitoes }\end{array}$ & Kenya & Boolean model and spatial lag model & Li et al. (2008) \\
\hline Age; socioeconomic status; & Spatially explicit risk mapping & Côte d'Ivoire & Geostatistical modelling & Silue et al. (2008)
\end{tabular}

use of bed nets; distance to

health facilities; NDVI; rainfall;

distance to rivers

Vector abundance; temperature; rainfall; water body; agro-ecological zone;

NDVI soil water index

Modelling spatial and temporal malaria incidence
Mozambique Spatial correlation nested to temporal Abellana et al. (2008) climate data and hierarchical

Bayesian models

Land cover; daily data for river water levels Mapping of vector breeding sites

Assessing the correlation between different chromosomal forms

Mali Bivariate multinomial regression models Sogoba et al. (2008)

of An. gambiae with climate factors

Sudan

Cross-sectional survey.

Ageep et al. (2009)

Bivariate and multivariate logistic regression modelling

Socio-economic status; land surface temperature; NDVI; rainfall; digital elevation model

Temperature; rainfall

Malaria prevalence data from the Senegal; Malaria indicator survey; climatic and environmental proxies socio-economic factors and malaria intervention measures
Assessing the relationship

between malaria risk, environment and socio-economic factors
Zambia

Bayesian geostatistical and spatial independent modelling
Assessing the association between malaria Mozambique incidence and climatic factors

Spatially explicit parasitaemia risk estimates and number of infected children under the age of 5

\section{Senegal}

Bayesian hierarchical model Zacarias and Andersson (2010)

Geostatistical ZIB models, Bayesian variable selection, Giardina et al. (2012) MCMC

TM, thematic mapper; NDVI, normalised difference vegetation index; ZIB, zero-inflated binomial; MCMC, Markov chain Monte Carlo. 
factors including age, socioeconomic status, use of bed nets, distance to health facilities, NDVI, rainfall, land surface temperature, and distance to rivers. The NDVI and land surface temperature were acquired from Moderate Resolution Imaging Spectroradiometer (MODIS) (https://ta.cr.usgs.gov/MODIS) at $1 \times 1 \mathrm{~km}$ spatial resolution, while rainfall estimated at $8 \times 8 \mathrm{~km}$ spatial resolution from Meteosat-7 satellite obtained from Africa Data Dissemination Service (ADDS). After conducting spatial correlation analysis only age was identified as a significant risk factor for malaria prevalence, whereas NDVI was borderline significant. Abellana et al. (2008) studied the seasonal effect on the spatial distribution of malaria incidence in a group of children less than 10 years old living in Manhica district in Mozambique. Poisson regression analysis was carried out to assess the relationship between malaria incidence and the covariates: sex, age groups, and climate season. The assessment presented a clear spatial pattern, with a higher incidence in the neighbourhoods situated in the north and northeast of the Manhica district. Malaria transmission decreased with age and was highest during the wet season, but the spatial pattern of malaria did not differ from that observed during the dry season. Diego et al. (2009) explored the influence of 17 eco-climatic variables which included climatic, topographic, and land use in determining the geographic distribution of five major malaria vectors (A. gambiae, A. funestus, $A$. arabiensis, $A$. nili and $A$. moucheti) in space and time in Cameroon. These mosquito species were collected from 386 villages using window traps. Spatial habitat suitability modelling and multivariate regression analysis techniques were used to determine the geographic distribution of these mosquito species across the country. The results showed that human related activities had the highest impact on habitat suitability for the five major malaria vectors, whereby areas of low population density were of unsuitable habitat quality. Understanding and modelling the ecological niche of vectors can be a powerful predictor of malaria transmission.

Li et al. (2008) mapped the distribution and abundance of mosquito vectors in the highlands of West Kenya using spatial modelling methods. GPS was used to record the coordinates of selected houses, and mosquitoes were collected using the indoor pyrethrum spray collection method. Mosquito abundance was measured as a density of female adult $A$. gambia s.l. at each house. Only female mosquitoes were included in the study because they are responsible for malaria transmission. Concurrently, the presence of $A$. gambia s.l. larvae in all aquatic habitats in the study area was thoroughly examined. Aquatic habitats with the presence of $A$. gambiae s.l. larvae were considered as mosquito breeding habitats and their coordinates were recorded. Three environmental variables namely, wetness index, distance to high-order streams, and distance to low-order streams were used to describe the density and abundance of mosquitoes. The method that was developed using spatial lag model confirmed that houses situated close to highorder streams were identified as an effective predictor for the distribution of adult mosquitoes. Similarly, the study conducted by Ageep et al. (2009) in two localities adjacent to Nile river in Sudan focused on mapping the spatial and seasonal dynamics of local vector density based on predetermined land cover classified with QuickBird satellite imagery (http:/glcf.umd.edu/data/quickbird/). Moreover, GPS was also used to collect points where mosquito larva was sampled, and the field data were integrated with remote sensing data in ArcGIS (ESRI, Redlands, CA, USA). Bivariate and multivariate logistic regression models were used to identify the characteristics of a breeding site which is associated with increased risk of larvae presence. The study showed that most positive sites were associated with temporary standing water around channel edges of the main Nile River. Close to the Nile channel, a distinct seasonal pattern in larval populations was evident and appeared to be linked to changes in water level. Similarly, Gaudart et al. (2009) used 15-day composites of the NDVI from remote sensing data between 1981 and 2006 for temporal modelling of malaria incidence in a locality of Bancoumana, Mali. The statistical relationship between NDVI and malaria incidence was assessed by Autoregressive Integrated Moving Average (ARIMA) time series analysis. The study showed that seasonal pattern of malaria incidence was significantly explained by NDVI with a delay of 15 days, and demonstrated that land cover types play an important role in the spatial distribution of anopheline habitats in Bancoumana, Mali.

More recently, Riedel et al. (2010) studied the geographic patterns of malaria risk in Zambia using environmental indicators of malaria transmission. These environmental indicators were extracted from

Table 3. Studies on malaria early warning systems.

\begin{tabular}{|c|c|c|c|c|}
\hline Type of data and source & Objective & Study area & Method & Reference \\
\hline $\begin{array}{l}\text { Satellite derived estimates } \\
\text { of rainfall and sea surface } \\
\text { temperature }\end{array}$ & $\begin{array}{l}\text { Development of malaria early } \\
\text { warning systems }\end{array}$ & Botswana & Pearson's product moment correlation coefficients & Thomson et al. (2005) \\
\hline $\begin{array}{l}\text { Malaria incidence } \\
\text { and climatic data }\end{array}$ & $\begin{array}{l}\text { Assessment of seasonal weather } \\
\text { forecast for seasonal prediction } \\
\text { of malaria epidemics }\end{array}$ & Tanzania & Regression analysis, DEMETER & Jones et al. (2007) \\
\hline $\begin{array}{l}\text { Monthly malaria cases; } \\
\text { monthly climatic data; } \\
\text { seasonal climate forecast; } \\
\text { satellite-derived rainfall; } \\
\text { NDVI }\end{array}$ & $\begin{array}{l}\text { Development of epidemiological } \\
\text { early warning systems }\end{array}$ & Eritrea & $\begin{array}{l}\text { Principal component analysis, } \\
\text { non-hierarchical clustering, } \\
\text { and correlation analysis }\end{array}$ & Ceccato et al. (2007) \\
\hline $\begin{array}{l}\text { Malaria cases, precipitation, } \\
\text { temperature and NDVI }\end{array}$ & $\begin{array}{l}\text { Development of } \\
\text { a seasonal malaria } \\
\text { epidemiological model in an area } \\
\text { of unstable transmission }\end{array}$ & Burundi & ARIMA time series analysis & Gomez-Elipe et al. (2007) \\
\hline Malaria cases and NDVI & $\begin{array}{l}\text { Forecast of the evolution } \\
\text { of malaria epidemiology }\end{array}$ & Mali & ARIMA time series analysis & Gaudart et al. (2009) \\
\hline
\end{tabular}

NDVI, normalised difference vegetation index; ARIMA, autoregressive integrated moving average. 
MODIS satellite remote sensing data. Bivariate logistic regression models were fitted to assess the relationships between malaria cases and environmental indicators. Results reported by these authors showed that high risk is characterised in the country mainly because of low altitude, high NDVI, and high day and night land surface temperatures. Zacarias and Andersson (2010) investigated if a relationship existed between the incidence of malaria and selected weather parameters in tropical Maputo province in Mozambique. A Bayesian hierarchical model was formulated that used malaria count data aggregated at district level over a two year period. The model included the environmental covariates temperature and rainfall, which associated with malaria incidence differently at different seasons of the year. The strength of the relationship also varied between consecutive years. Giardina et al. (2012) estimated the burden of malaria in Senegal using Bayesian zero-inflated binomial geo statistical modelling using malaria prevalence data from Senegal Malaria Indicator Survey (SMIS). These models were developed to cope with the large number of zero-prevalence locations in the data. Best set of climatic and environmental parameters were identified by Bayesian variable selection method, and the spatially explicit parasitaemia risk as well as the number of infected children under the age of five were estimated. The covariates that defined the models with the highest posterior probabilities were night LST, NDVI and area type (urban/rural). The effectiveness of interventions was also investigated by calculating intervention indicators, and the results showed that at least one available insecticide treated bed net per every two household members, was most related with the parasitaemia risk after adjusting for climatic or environmental factors, age and wealth index.

\section{Spatial technologies for malaria early warning sys- tems}

Spatial technologies provide means for assessment, monitoring and modelling of ecological and climatic variables over a large area and through time that may indicate areas of malaria risk. Malaria risk models typically use many of the ecological and climatic variables discussed in the previous section. Statistical models identify the most significant predictors of disease transmission and provide a mathematical description of the disease-predictors relation that can be used for prediction. The main focus of this section of the review is on the established statistical relationships between malaria epidemiology and a range of climatic and environmental variables used to enable the prediction of temporal malaria epidemics to develop malaria early warning systems. However, in an area where malaria transmission is stable, the prevalence of malaria is high and endemicity is relatively insensitive to climatic variables. Malaria transmission stability occurs when extrinsic development of the parasite is short, when anophelines and humans are highly susceptible to infection, and when the vectors have a low mortality rate and bite human frequently (Hay and Pettitt, 2001). Africa can be viewed as stable for malaria transmission with instability increasing towards its latitudinal and altitudinal limits (Hay and Pettitt, 2001). This occurs towards the northern and southern fringe of the continent where arid conditions lead to decreased opportunities for mosquito breeding, and increased larva and adult mortality. Furthermore, when moving up into highland areas the extrinsic incubation period of the parasite is significantly prolonged owing to a decrease in average temperature.

Applications of spatial technologies for spatio-temporal malaria epidemic prediction performed to date in Africa are summarised in Table 3 . There is growing recognition of the need to implement programmes to predict and prevent malaria epidemics.

The early detection, containment and prevention of malaria epi- demics constitute one of the four elements of the global malaria control strategy (WHO, 2001). There is growing recognition of the need to implement programmes to predict malaria epidemics. Few studies were carried out to develop malaria early warning systems taking environmental variables into account. Thomson et al. (2005) reported a methodology for assessing the importance of climate as a drive for inter-annual malaria variability in Botswana, and also provided the evidence base to include climate information in a national malaria early warning systems. The relationship of climate variability, as predicted by the Climate Prediction Center (CPC) using the CPC Merged Analysis of Precipitation (CMAP), which produces analyses of global precipitation in which observations from raingauges are merged with precipitation estimates from several satellite-based algorithms (infrared and microwave), was used to assess the effect of rainfall and surface temperatures on malaria incidence at national level excluding the impact of non-climatic trends for major policy interventions. In Botswana, variability in rainfall totals for the period December to February accounted for more than two-thirds of the inter-annual variability in standardised malaria incidence between January and May. Both rainfall and annual malaria incidence between December and February were significantly related to sea surface temperatures in the eastern Pacific, which suggested that climate forecasting methodologies can be used to predict malaria incidence. The developed linear model explained more than $75 \%$ of the inter-annual variance, while the use of a quadratic relationship between CMAP rainfall and log malaria incidence was supported by a significant improvement in model fit, whereby $85 \%$ of the variance could be explained.

Jones et al. (2007) assessed the ability of the Development of European Multi-model Ensembles Forecast System for Seasonal to International Climate Prediction (DEMETER) for predicting climate variances that are associated with malaria epidemics which occurred in 1997 and 1998 in Kagera, Tanzania. Initially, a regression analysis was performed on retrospective malaria and climatic data during each of the two annual malaria seasons to determine the climatic factors influencing malaria incidence. In the subsequent step, the ability of DEMETER in predicting the climatic anomalies associated with malaria epidemics was then assessed for each malaria season. It was found that malaria incidence was positively correlated with rainfall during the first season (October-March) with a $\mathrm{R}^{2}$ of $0.73, \mathrm{P}<0.01$. For the second season (April-September), high malaria incidence was associated with increased rainfall, but also with high maximum temperature during the first rainy season (multiple $\mathrm{R}^{2}$ of $0.79, \mathrm{P}<0.01$ ). They concluded that DEMETER was unable to predict the heavy El Niño rains associated with the malaria epidemics occurred in 1997 and 1998. However, these epidemics could have been predicted using the temperature forecasts alone. They recommended that the consideration of rainfall forecasts would have improved the forecasts of malaria epidemics that only based on temperature. Ceccato et al. (2007) developed a malaria epidemic early warning systems in Eritrea. Monthly clinical malaria cases were used to stratify areas with distinct malaria intensity using principal component analysis and non-hierarchical clustering techniques. Relationship between monthly clinical malaria cases and monthly climate data from several sources including remotely sensed data and seasonal climate forecasts were investigated. Results showed that rainfall from gauge data provides prediction of malaria incidences with a lead time of 2-3 moths for some districts with sufficient meteorological stations. Whereas, satellite derived normalised difference vegetation index (NDVI) provides concurrent prediction of malaria incidence particularly in the semi-arid north of the country and along the coast in the Northern Red Sea.

Gomez-Elipe et al. (2007) developed a model to predict the spatial 
and temporal malaria incidence in Karuzi, a province in the Burundi highlands, an area of unstable transmission, by studying the relationship between environmental variables and disease dynamics. The environmental variables used were monthly cumulative precipitation, minimum and maximum temperature obtained from Karuzi meteorological station. Monthly NDVI data derived from the Very High Resolution Radiometer (AVHRR) (http://noaasis.noaa.gov/NOAASIS/ml/avhrr.html) from United States's National Oceanic and Atmospheric Administration (NOAA) (http://www.noaa.gov/) was also used with a spatial resolution of $8 \times 8 \mathrm{~km}$. As a first step, the autoregressive integrated moving average (ARIMA) method (https://www.otexts.org/fpp/8) was employed to develop a model that shows the relation between monthly notifications of malaria cases and the environmental variables. Finally, a prediction model was developed using time series analysis. The model constructed by the author attempts to provide estimates of the expected incidence of malaria one months in advance based on the current observed incidence rate and a combination of climatic factors (temperature, rainfall, and vegetation index). The model explains a substantial percentage of the observed variability in the malaria rate with a $\mathrm{R}^{2}$ of 0.82 . Similarly, Gaudart et al. (2009) used 15 day composite NDVI data derived from NOAA AVHRR for modelling malaria incidence in a locality of Sudanese savannah area, Mali. Incidence data was obtained from a field study done from 1996 to 2001. The study included 173 of the 340 households selected from four geographic blocks of the village using a stratified random sampling. The statistical relationship between NDVI and malaria incidence was assessed by ARIMA time series analysis. The seasonal pattern of malaria incidence was significantly explained by the NDVI with a delay of 15 days. The value of $R^{2}=0.89$ was relatively high. The authors concluded that the statistical model using only NDVI as covariate showed a satisfactory goodness-of-fit.

Remote sensing has become an indispensable information source about environmental parameters. At present study limitations are often due to low spatial resolution of remotely sensed environmental data (Mabaso and Ndlovu, 2012). However, with the recent launch of new and high-performance satellites, it has become possible to make use of higher resolution remote sensing data for assessing some environmental factors. Currently numerous satellite missions such as, IKONOS-2, QuickBird-2, KOMPSAT-2 (https://earth.esa.int/web/ guest/missions/ 3rd-party-missions/current-missions/kompsat-2), Pleiades (http://www.geo-airbusds.com/pleiades/) as well as GeoEYE-1 and WorldView-2 (https://www.digitalglobe.com/about/our-constellation) and their successors provide suitable data for local studies on malaria epidemiology, since even small land cover features can be detected with the very high spatial resolutions available today (now having reached $1.7 \mathrm{~m}$ multispectral resolution). For regional studies, satellite systems with a larger spatial coverage (wider swaths) are required. These include high resolution systems like RapidEye (http://eyefind.rapideye.com/), SPOT-6/7 (http://www.geo-airbusds.com/en/147-spot-6-7satellite-imagery), FORMOSAT (http:/www.geo-airbusds.com/en/160formosat-2) (between $10 \mathrm{~m}$ and $2 \mathrm{~m}$ multispectral) or the upcoming Sentinel mission or moderate resolution systems like Landsat, ASTER (http://www.geoimage.com.au/satellite/aster) or the Disaster Monitoring Constellation (DMC) (http://www.sstl.co.uk/getdoc/ e8f7eb18-078f-4254-a7af-db1e64326ade).

\section{Discussion}

Studies using spatial technologies with the applications targeted on studying malaria epidemiology and control in Africa have shown the potential of mapping malaria incidence/prevalence, identifying environmental variables that impact malaria risk and developing malaria early warning systems. Nonetheless, several important issues remain to be addressed and require further studies in order to refine the tools and broaden their impact on malaria control strategies. This review paper is focused on the role of spatial technologies, i.e. remote sensing, GIS, geostatistics, spatial analysis and spatial modelling and provides an insight into the opportunities offered by spatial technology for enhanced malaria disease investigation. In the last two decades, researchers have started to use spatial data for malaria risk mapping as the importance of spatial explicit processes in determining malaria risk is becoming more widely acknowledged in operational malaria control (Mabaso and Ndlovu, 2012). Developments in the application of spatial technologies over the last two decades have enhanced the acquisition, storage, retrieval, analysis and visualisation of spatial data, approaches of great potential for an increased understanding of the link between malaria and its dependence on environmental variables. The variables considered in this review were rainfall, temperature, land cover features, NDVI, socio-economic or demographic data, altitude, soil moisture and malaria control interventions. It should, however, be admitted that although they show a strong correlation with malaria epidemiology, their spatial resolution is coarse/low for local malaria transmission modelling.

This review illustrates how spatial technologies facilitate the monitoring and management of control programs, and open new avenues for multidiscipline collaboration. These techniques can be successfully used only in conjunction with a thorough understanding of environmental and epidemiologic processes of malaria transmission. As suggested by Delgado-Petrocelli et al. (2011), using an integrated spatial technology including ecological, climatic and epidemiological data, the relationship between geographic features, human activities, and malaria prevalence/incidence can be investigated. However, there is still no operational monitoring system available which, for example, allows monthly mapping of environmental suitability for malaria transmission throughout Africa.

Numerous studies have applied spatial technologies in combination with spatial statistics and Bayesian geostatistics for malaria case mapping and predictive modelling of malaria distribution for developing early warning systems in Africa. However, there is a scope for application of novel spatial technologies and innovative use of already available satellite information, notably qualitative, spatial methods that hold promise for more detailed, precise and accurate applications. Spatial technology has the potential to further improve current approaches and strategies for malaria vector control and management in Africa, and in turn inspire control programmes elsewhere.

The higher the spatial resolution of satellite systems, the more detailed studies on the relationships between malaria transmission and land cover/use can be conducted. With such resolutions reaching below $2 \mathrm{~m}$, even small water bodies can be detected that might play an important role as potential vector breeding sites. However, low resolution satellite systems such as MODIS, NOAA AVHRR or Meteosat provide large area monitoring of climate variables that must be considered for modelling malaria risk.

Previous applications remain short in discussing issues related to sample sizes and spatio-temporal patterns in malaria disease. Mapping prevalence data derived from cross-sectional epidemiological surveys can be non-informative or even misleading when the sample sizes of the population for some of the units are small, resulting in large variability in the estimated prevalence. In such circumstances, it is difficult to distinguish chance variability from genuine differences. Pooling of neighbouring units often masks important real differences, which in 
turn is of relevance for the identification of the underlying causes. Recent progress in empirical Bayes and Bayesian hierarchical modelling provided new opportunities to overcome some of these problems, since stable estimates can be obtained for small areas using information obtained from neighbouring areas. The development of this field has been greatly advanced by rapidly developing computational tools such as Gibbs sampler (Casella and Georg, 1992) as well as other Markov chain Monte Carlo (MCMC) methods for posterior analyses. At present, there is a considerable body of literature pertaining to Bayesian based geo-statistical analyses of malaria risk. The first applications, with an aim to further enhance our understanding of malaria epidemiology and control in Africa, have been reported to produce promising results at country and regional scale.

There is substantial potential for malaria risk monitoring that can help initiate malaria control efforts prior to disease epidemics. In the years ahead, spatial technologies will have a profound impact on malaria control strategies involving malaria surveillance, risk assessment and early warning systems. Despite the perceived expense, several of the studies have demonstrated that spatial technologies can be costeffective components of malaria vector control campaigns, which anticipates well for their future operational applications.

\section{Conclusions}

Spatial analysis techniques rely on data acquired by earth observation systems that have the potential to revolutionise research and operationalise studies in malaria epidemiology as they acquire unparalleled amounts of data about the earth surface with synoptic cover at a variety of spatial and temporal resolutions. The constellation of satellites currently orbiting the Earth supports highly precise co-ordinate identification of environmental variables in remote and poorly mapped areas of the continent. Spatial technology has significantly contributed to the study of malaria risk and transmission, and its potential role for early warning of malaria epidemics. Investing more efforts in establishing an interdisciplinary research agenda including training workshops and seminars, in which medical researchers, epidemiologists and spatial technology researchers can streamline the topics along pragmatic lines, would provide opportunities for experts to exchange ideas and share the results of their latest work.

\section{References}

Abellana R, Ascaso C, Aponte J, Saute F, Nhalungo D, Nhacolo A, Alonso $\mathrm{P}, 2008$. Spatio-seasonal modelling of the incidence rate of malaria in Mozambique. Malaria J 7:228.

Ageep TB, Cox J, Hassan MM, Knols BG, Benedict MQ, Malcolm CA, Babiker A, El-Sayed B, 2009. Spatial and temporal distribution of the malaria mosquito Anopheles arabiensis in northern Sudan: influence of environmental factors and implications for vector control. Malaria J 8:123.

Blanford JL, Blanford S, Crane RG, Mann ME, Paaijmans KP, Schreiber $\mathrm{KV}$, Thomas MB, 2013. Implications of temperature variation for malaria parasite development across Africa. Sci Rep 3:1300.

Bøgh C, Lindsay SW, Clarke SE, Dean A, Jawara M, Pinder M, Thomas CJ, 2007. High spatial resolution mapping of malaria transmission risk in the Gambia, West Africa, using Landsat TM Satellite Imagery. Am J Trop Med Hyg 76:5.
Booman M, Sharp BL, Martin CL, Manjate B, La Grange JJ, Durrheim DN, 2003. Enhancing malaria control using a computerised management system in southern Africa. Malaria J 2:13.

Casella G, Georg EI, 1992. Explaining the Gibbs sampler. Am Stat 46:167-74.

Ceccato P, Ghebremeskel T, Jaiteh M, Graves PM, Levy M, Ghebreslassie S, Ogbamariam A, Barnston AG, Bell M, del Corral J, Fesseha I, Brantly EP, Thomson MC, 2007. Malaria stratification, climate and epidemic early warning in Eritrea. Am J Trop Med Hyg 77:61-8.

Craig MH, Kleinschmidt I, Nawn JB, Le Sueur D, Sharp BL, 2004. Exploring 30 years of malaria case data in KwaZulu-Natal, South Africa: Part I. The impact of climate factors. Trop Med Int Health 9:1247-57.

Craig MH, Sharp BL, Mabaso MLH, Kleinschmidt I, 2007. Developing a spatial-statistical model and map of historical malaria prevalence in Botswana using a staged variable selection procedure. Int $\mathrm{J}$ Health Geogrs. 6:44.

Craig MH, Snow RW, le Sueur D, 1999. A climate-based distribution model of malaria transmission in sub-Saharan Africa. Parasitol Today 15:105-11.

Delgado-Petrocelli L, Camardiel A, Aguilar VH, Martinez N, Cordova K, Ramos S, 2011. Geospatial tools for the identification of a malaria corridor in Estado Sucre, a Venezuelan north-eastern state. Geospat Health 5:169-76.

Diego A, Carlo C, Kenji 0, Guy CK, Christophe A, Jean-Pierre A, Parfait A, Didier F, Frederic S, 2009. Habitat suitability and ecological niche profile of major malaria vectors in Cameroon. Malaria J 23:1.

Gallup JL, Sachs D, 2001. The economic burden of malaria. Am J Trop Med Hyg 64:85-96.

Gaudart J, Toure 0, Dessay N, Dicko A, Ranque S, Forest L, Demongeot $\mathrm{J}$, Doumbo 0, 2009. Modelling malaria incidence with environmental dependency in a locality of Sudanese savannah area, Mali. Malaria J 8:61.

Giardina F, Gosoniu L, Konate L, Diouf MB, Perry R, 2012. Estimating the burden of malaria in Senegal: Bayesian zero-inflated binomial geostatistical modeling of the MIS 2008 Data. PLoS One 7:e32625.

Gomez-Elipe A, Otero A, van Herp M, Aguirre-jaime A, 2007. Forcasting malaria incidence based on monthly case reports and environmental factors in Karuzi, Burundi, 1997-2003. Malaria J 6:129.

Gosoniu L, Veta AM, Vounatsou P, 2010. Bayesian geostatistical modeling of malaria indicator survey data in Angola. PLoS 0ne 5:e9322.

Guerra CA, Snow RW, Hay SI, 2006. Mapping the global extent of malaria in 2005. Trends Parasitol 22:353-8.

Hay SI, Omumbo JA, Craig MH, Snow W, 2000. Earth observation, geographic information systems and Plasmodium falciparum malaria in Sub-Saharan Africa. Adv Parasit 47:173-215.

Hay SI, Pettitt AN, 2001. Bayesian analysis of a time series of counts with covariates: an application to the control of an infectious disease. Biostatistics 2:433-44.

Hayes R0, Maxwell EL, Mitchell CJ, Woodzick TL, 1985. Detection, identification, and classification of mosquito larval habitats using remote sensing scanners in earth-orbiting satellites. B World Health Organ 63:361-74.

Jones AE, Wort UU, Morse AP, Hastings IM, Gagnon AS, 2007. Climate prediction of El Niño malaria epidemics in northern-west Tanzania. Malaria J 6:162.

Kazembe LN, 2007. Spatial modelling and risk factors of malaria incidence in northern Malawi. Acta Trop 102:126-37.

Kazembe LN, Kleinschmidt I, Holtz TH, Sharp BL, 2006. Spatial analysis and mapping of malaria risk in Malawi using point-referenced prevalence of infection data. Int J Health Geogr 5:41. 
Kelly GC, Tanner M, Vallely A, Clements A, 2012. Malaria elimination: moving forward with spatial decision support systems. Trends Parasitol 28:297-304.

Li L, Ling B, Guiyun Y, 2008. A study of the distribution and abundance of the adult malaria vector in western Kenya highlands. Int $\mathbf{J}$ Health Geogr 7:50.

Mabaso MLH, Ndlovu NC, 2012. Critical review of research literature on climate-driven malaria epidemics in Sub-Saharan Africa. Public Health 26:909-19.

MARA/ARMA, 2008. Available from: http://www.webcitation.org/getfile?fileid=aaae5628df7d5e7ae20b3 ddd8c2a9365dfb00614

Mboera LE, Senkoro KP, Mayala BK, Rumisha SF, Rwegoshora RT, Mlozi MR, Shayo EH, 2010. Spatio-temporal variation in malaria transmission intensity in five agro-ecosystmes in Mvomero district, Tanzania. Geospat Health 4:167-78.

Mendis K, Rietveld A, Warsame, Bosman A, Greenwood B, Wernsdorf WH, 2009. From malaria control to eradication: the WHO perspective. Trop Med Int Health 14:802-9.

Mills A, Lubell Y, Hanson K, 2008. Malaria eradication: the economic, financial and institutional challenge. Malaria J 7:11.

Moshe BH, Andrew PM, 2004. A weather-driven model of malaria transmission. Malaria J 3:32.

Noboru M, Stephen M, Francis A, Emmanuel M, Guofa Z, Andrew KG, Guiyun Y, 2005. Spatial distribution of anopheline larval habitats in western Kenyan highlands: effects of land cover types and topography. Am J Trop Med Hyg 73:1.

Noor AM, Clements ACA, Gething PW, Moloney G, Borle M, Shewchuk T, Hay SI, Snow RW, 2008. Spatial prediction of Plasmodium faciparum prevalence in Somalia. Malaria J 7:159.

Oesterholt M, Bousema JT, Mwerinde OK, Harris C, Lushino P, Masokoto A, Mwerinde H, Mosha FW, Drakeley CJ, 2006. Spatial and temporal variation in malaria transmission in a low endemicity area in northern Tanzania. Malaria J 5:98.

Raso G, Schur N, Utzinger J, Koudou G, Tchicaya ES, Rohner F, N'Goran EK, Silue KD, Matthys B, Assi S, Tanner M, 2012. Mapping malaria risk among children in Cote d'Ivoire using Bayesian geo-statistical models. Malaria J 11:160.

Riedel N, Vounatsou P, Miller JM, Gosoniu L, Chizema-Kawesha E, Mukonka V, Steketee RW, 2010. Geographic patterns and predictors of malaria risk in Zambia: Bayesian geostatistical modelling of the 2006 Zambia national malaria indicator survey. Malaria J 9:37.

Silue KD, Raso G, Yapi A, Vounatsou P, Tanner M, Goran EKN, Utzinger J, 2008. Spatially-explicit risk profiling of Plasmodium falciparum infections at a small scale: a geo-statistical modelling approach. Malaria J 7:11.
Smith DL, Dushoff J, McKenzie FE, 2004. The risk of a mosquito-borne infection in a heterogeneous environment. PLoS Biol 2:e2368.

Snow RW, Marsh K, Le Sueur D, 1996. The need for maps of transmission intensity to guide malaria control in Africa. Parasitol Today 12:455-6.

Sogoba N, Vounatsou P, Bagayoko MM, Dolo G, Gosoniu L, Traore SF, Toure YT, Smith T, 2007. The spatial distribution of Anopheles gambiae sensu stricto and An. arabiensis (Diptera: Culicidae) in Mali. Geospat Health 1:213-22.

Sogoba N, Vounatsou P, Bagayoko MM, Doumbia S, Dolo G, Gosoniu L, Traore SF, Smith TA, Touré YT, 2008. Spatial distribution of the chromosomal forms of Anopheles gambiae in Mali. Malaria J 7:205.

Stensgaard AS, Vounatsou P, Onapa AW, Simonsen PE, Pedersen EM, Rahbek C, Kristensen TK, 2011, Bayesian geostatistical modelling of malaria and lymphatic filariasis infections in Uganda: predictors of risk and geographical patterns of co-endemicity. Malaria $\mathrm{J}$ 10:298.

Tanser FC, le Sueur D, 2002. The application of geographical information systems to important public health problems in Africa. Int $\mathbf{J}$ Health Geogr 1:4.

Thomas K, Friederik D, Jügen S, 2002. New perspectives on the use of Geographical Information Systems (GIS) in environmental health sciences. Int J Hyg Environ Health 205:169-81.

Thomson MC, Doblas-reyes FJ, Mason SJ, Hagedorn R, Connor SJ, Phindela T, Morse AP, Palmer TN, 2006. Malaria early warnings based on seasonal climate forecasts from multi-model ensembles. Nature 439:576-9.

Thomson MC, Mason SJ, Phindela T, Connor SJ, 2005. Use of rainfall and sea surface temperature monitoring doe malaria early warning in Botswana. Am J Trop Med Hyg 73:214-21.

WHO, 2001. Malaria early warning systems, concepts, indicators and partners. A framework for field research in Africa. World Health Organization, Geneva, Switzerland.

WHO, 2012. WHO global malaria programme: world malaria report. World Health Organization, Geneva, Switzerland.

Ye Y, Louis VR, Simboro S, Sauerborn R, 2007, Effect of meteorological factors on clinical malaria risk among children: an assessment using village-based meteorological stations and community-based parasitological survey. BMC Public Health 7:101.

Yeshiwondim AK, Gopal S, Hailemariam AT, Dengela D0, Patel H, 2009. Spatial analysis of malaria incidence at the village level in areas with unstable transmission in Ethiopia. Int J Health Geogr 8:5.

Zacarias 0, Andersson M, 2010. Mapping malaria incidence distribution that accounts for environmental factors in Maputo ProvinceMozambique. Malaria J. 9:79. 